\title{
ANALISIS KESULITAN MAHASISWA DALAM KEGIATAN PRAKTIKUM DI LABORATORIUM
}

\section{ANALYSIS OF STUDENT DIFFICULTIES IN PRACTICAL ACTIVITIES IN SCIENCE LABORATORY}

\author{
Mohammad Liwa Ilhamdi ${ }^{1}$, Sukib $^{2}$ dan Jannatin Ardhuha ${ }^{3}$ \\ ${ }^{1}$ Program Studi Pendidikan Biologi FKIP, Universitats Mataram, Mataram, Indonesia \\ ${ }^{2}$ Program Studi Pendidikan Kimia FKIP, Universitats Mataram, Mataram, Indonesia \\ ${ }^{3}$ Program Studi Pendidikan Fisika FKIP, Universitats Mataram, Mataram, Indonesia \\ Email: $\underline{\text { liwa_ilhamdi@unram.ac.id }}$
}

Diterima: 15 Februari 2020. Disetujui: 17 Februari 2020. Dipublikasikan: 31 Maret 2020

\begin{abstract}
Abstrak: Tujuan Penelitian ini adalah menganalisis kesulitan yang dihadapi mahasiswa dalam melaksanakan kegiatan praktikum di laboratorium PMIPA FKIP Universitas Mataram tahun 2016. Populasi dalam penelitian ini adalah seluruh mahasiswa PMIPA FKIP Universitas Mataram berjumlah 703 orang. Tehnik pengambilan sampel adalah proporsional stratified random sampling. Pengumpulan data dengan menggunakan kuesioner skala linkert. Data dianalisis menggunakan analisis persentase tingkat kesulitan. Hasil penelitian menunjukkan bahwa kesulitan yang dihadapi mahasiswa dalam kategori cukup sulit adalah mahasiswa tidak nyaman melakukan kegiatan praktikum karena ruang laboratorium panas( 60\%), tingkat kehadiran dosen yang rendah (58\%) dan kekurangan alat praktikum (55\%) Sedangkan kategori kurang menyulitkan adalah hasil pretes dan postest praktikum jarang dikembalikan ke mahasiswa(32\%), kurang paham dengan penjelasan co Assisten (30\%) dan laporan praktikum banyak jenisnya (29\%). Kesimpulan penelitian ini adalah urutan kesulitan yang dihadapi mahasiswa dalam melaksanakan kegiatan praktikum di PMIPA FKIP Unram adalah ruang praktikum yang panas, kehadiran dosen pembimbing rendah, kekurangan alat praktikum, hasil pretes dan postes tidak dikembalikan ke praktikan, kurang paham dengan penjelasan co assisten tentang materi praktikum dan terlalu banyak jenis laporan praktikum.
\end{abstract}

Kata Kunci: Analisis, Kesulitan, praktikum, laboratorium

\begin{abstract}
Abstrack: The aim of this study is to analyze of student difficulties in practical activities in science laboratory faculty of teacher training and education university of mataram in 2016. The population in this study is all students of mathematics and science education amounted to 703 people. The sampling technique is proportional stratified random sampling. Data collection using a linkert scale questionnaire. Data were analyzed using percentage analysis of difficulty level. The result of the research shows that the difficulties by students in the category are quite difficult is the students are not comfortable doing practicum activity because the laboratory room is hot $(60 \%)$, low lecturer attendance $(58 \%)$ and lack of practicum tool $(55 \%)$ While the less difficult category is pretest and posttest results are rarely returned to college students (32\%), less well understood by counseling Assists (30\%) and practicum reports of many kind (29\%). The conclusion of this study is the sequence of difficulties in practical activity by students are hot practicum room, the presence of low lecturers, lack of practicum tools, the results of pretest and postes not returned to students, not understand by the explanation co assisten about practical materials and too many types of report.
\end{abstract}

Keywords: Analysis, Difficulty, practice, laboratory

\section{PENDAHULUAN}

Laboratorium PMIPA FKIP Universitas Mataram merupakan tempat mahasiswa dan dosen melakukan percobaan, memantapkan penguasaan pengetahuan dan mengembangkan pengetahuan, mengembangkan keterampilan proses dan keterampilan intelektual seperti mengamati, mengklasifikasikan. mengukur, mencari hubungan antar konsep yang satu dengan yang lain, berhipotesis, meramalkan, berkomunikasi, bereksperimen, membuat model, keterampilan menggunakan alat dan sebagainya, tempat membina sikap, dan tempat berdemonstrasi, berdiskusi, melakukan penelitian, dan berlatih berpikir produktif yaitu kritis, logis, kreatif dan teratur, memiliki layanan pemeriksaan laboratorium khusus untuk memenuhi kebutuhan analisis mikrobiologis, foto mikroskop. Laboratorium PMIPA FKIP Universitas Mataram juga memberikan layanan penunjang penelitian untuk mendukung berbagai penelitian mahasiswa dan dosen untuk tujuan akademis, dan publikasi ilmiah. Selama 2 tahun terakhir ini sudah lebih dari 30 judul penelitian para mahasiswa dan dosen yang didukung oleh Laboratorium PMIPA FKIP Universitas Mataram.

Sarana dan prasarana laboratorium yang memadai akan membantu mahasiswa dalam menghadapi kesulitan belajar terutama dalam penguasaan konsep yang bersifat abstrak. Adapun penyebab kesulitan belajar siswa adalah hambatan- 
hambatan yang dialami mahasiswa dalam proses pembelajaran. Hambatan yang dimaksud yaitu; pada kompetensi pendukung dalam penguasaan konsep, pada proses pembelajaran, dan pada faktor lingkungan mahasiswa [1]. Kesulitan belajar merupakan suatu kondisi yang dialami siswa atau mahasiswa yang ditandai dengan adanya hambatanhambatan tertentu yang menyebabka tidak tercapainya tujuan belajar. Terdapat berbagai faktor yang mempengaruhi ketidak tercapaian tujuan belajar yang terukur pada keberhasilan pembelajaran yaitu: kapasitas mahasiswa, kualitas guru/dosen, kualitas lingkungan pembelajaran, dan kualitas proses pembelajaran. Dari keempat faktor tersebut, dua yang Faktor yang paling dominan mempengaruhi keberhasilan pembelajaran yaitu; kapasitas mahasiswa, kualitas guru dan kualitas proses pembelajaran [2]. Untuk meningkatkan kuliatas pembelajaran adalah dengan memanfaatkan saran laboratorium sebagai penunjang pembelajaran sains.

Kelancaran praktikum laboratorium ditunjang oleh sarana dan prasarana laboratorium yang lengkap, manajemen laboratorium, dan pelayanan yang baik. Pelayanan adalah hasil yang ditimbulkan oleh kegiatan pada titik temu antara pihak laboratorium dan pengguna (mahasiswa dan dosen) dan oleh berbagai kegiatan internal laboratorium [3]. Pelayanan dinilai tidak memuaskan jika pengharapan tidak dipenuhi, memuaskan jika dipenuhi dan lebih dari memuaskan jika pengharapan itu dilampaui [4]. Laboratorium yang berhasil adalah mampu memenuhi harapan pengguna, antara lain praktikum dan penelitian berjalan sesuai rencana, tepat waktu, dan data yang diperoleh dari praktikum maupun penelitian adalah data yang valid.

Permasalahan yang dihadapi oleh Laboratorium PMIPA FKIP Universitas Mataram adalah meningkatnya jumlah mahasiswa yang menggunakan laboratorium baik untuk praktikum maupun penelitian tetapi sarana dan prasarana dalam 3 tahun terakhir tidak bertambah. Bahkan banyak peralatan laboratorium dalam kondiri rusak ringan dan rusak berat. Demikian juga tidak diterapkannya sistem manajemen laboratorium yang sebagaimana dipersyaratkan dalam ISO 17025: 2008. Hal ini mengakibatkan kurang maksimalnya pelayanan laboratorium PMIPA FKIP Universitas Mataram. Permasalahan ini tentu mengundang kesulitan bagi pengguna laboratorium khususnya mahasiswa. Adapun tujuan dari penelitian ini adalah untuk menganalisis kesulitan yang dihadapi mahasiswa dalam kegiatan praktikum di laboratorium PMIPA FKIP Universitas Mataram tahun 2016.

\section{METODE PENELITIAN}

Penelitian ini dilaksanakan di Laboratorium PMIPA FKIP Universitas Mataram dengan waktu penelitian akan dilaksanakan selama 8 bulan dari bulan April - November 2016. Jenis penelitian yang digunakan dalam penelitian ini adalah penelitian survey. survey merupakan cara pengumpulan data dari sejumlah unit atau individu dalam waktu atau kurun waktu bersamaan. Pengumpulan informasi dari responden yang terpilih dilaksanakan dengan kuesioner berupa daftar pertanyaan yang telah disiapkan [5].

Populasi dalam penelitian ini adalah seluruh mahasiswa PMIPA FKIP Universitas Mataram berjumlah 703 orang terdiri dari program studi biologi 176 orang, fisika 158 orang prodi matematika 193 orang, dan kimia 176 orang. Pengambilan sampel dilakukan pada setiap jenjang semester. Tehnik pengambilan sampel adalah proporsional stratified random sampling dengan jumlah sampel 15\% (106 orang).

Rancangan (Desain) penelitian survey yang digunakan merupakan cara pengumpulan data dari sejumlah unit atau individu dalam waktu atau kurun waktu bersamaan. Survei dimaksudkan adalah survei dengan membatasi pada sampel dimana informasi dikumpulkan dari sebagian populasi. Survei dilakukan pada Laboratorium PMIPA FKIP Universitas Mataram hanya mengungkapkan data berdasarkan hasil pengukuran pada gejala yang telah ada secara wajar pada diri responden, yang selanjutnya dilakukan rekontruksi dan identifikasi terhadap kesulitan mahasiswa melaksanakan kegiatan praktikum di laboratorium PMIPA FKIP Unram.

Jenis instrument yang digunakan dalam penelitian ini untuk mengukur setiap variabel yang diteliti menggunakan skor yang mengacu pada penggunaan Skala Likert, digunakan untuk mengukur sikap, pendapat dan persepsi seseorang atau kelompok orang tentang fenomena $[6,12,13]$.

Sebelum kuesioner digunakan untuk mengambil data, dilakukan dahulu uji validitas dan reliabelitas tes. Instrumen yang valid dan reliable digunakan untuk mengambil data penelitian.

Data dianalisis menggunakan analisis persentase tingkat kesulitan dengan kategori 0-25\% kategori tidak ada kesulitan, 26-50\% kategori kurang mengalami kesulitan, 51-75\% cukup mengalami kesulitan dan 76-100\% kategori mengalami kesulitan dalam praktikum.

\section{HASIL DAN PEMBAHASAN Tingkat Kesulitan pada Aspek Internal Mahasiswa}

Kesulitan internal yang menonjol dihadapi mahasiswa adalah pada indikator perhatian dan keaadaan kesehatan pada saat praktikum menunjukkan bahwa 9,4\% mahasiswa tidak berminat, 7,5\% mahasiswa sering kurang sehat dan $6,6 \%$ mahasiswa tidak punya motivasi dan minat dalam melakukan kegiatan praktikum. Hal ini terjadi karena kegiatan praktikum dimulai setelah kuliah 
berlangsung sehingga perhatian, minat, motivasi dan kesegaran tubuh menjadi berkurang (tabel 4.1). Faktor Internal pada indikator motivasi, perhatian, minat dan keadaan kesehatan tidak mempengaruhi kegiatan praktikum mahasiswa. Faktor-faktor yang menyebabkan kesulitan belajar siswa dalam belajar untuk masing-masing indikator dengan beberapa kualifikasi, baik faktor intern maupun ekstern [7]. Selain itu, faktor yang bersumber dari lingkungan diri sendiri memberikan kontribusi yang cukup terhadap perkembangan mahasiswa yang dapat menyebabkan kesulitan atau tidaknya mahasiswa dalam belajar maupun praktikum [8].

\section{Tingkat Kesulitan pada Aspek eksternal mahasiswa}

Secara eksternal faktor kesulitan yang paling banyak dihadapi pada kategori cukup menyulitkan melaksanakan kegiatan praktikum adalah pada indicator ruang laboratorium panas atau tidak nyaman ( $60 \%)$, tingkat kehadiran dosen yang rendah $(58 \%)$ dan kekurangan alat praktikum $(55 \%)$ Sedangkan kategori kurang menyulitkan adalah hasil pretes dan postest praktikum jarang dikembalikan ke mahasiswa(32\%), kurang paham dengan penjelasan co Assisten (30\%) dan laporan praktikum banyak jenisnya(29\%) (tabel 4.2).

Tabel 4.1. Tingkat kesulitan mahasiswa melaksanakan praktikum dari faktor internal

\begin{tabular}{llcccc}
\hline Faktor & Indikator & $\begin{array}{c}\text { Jml } \\
\text { Respon } \\
\text { den }\end{array}$ & Frekuensi & $\begin{array}{c}\text { Persentase } \\
\text { Kesulitan }\end{array}$ & $\begin{array}{c}\text { Kategori tingkat } \\
\text { kesulitan } \\
\text { melaksanakan } \\
\text { praktikum }\end{array}$ \\
\hline Internal & Tidak ada Motivasi & 106 & 7 & 6,6 & Tidak menyulitkan \\
& Tidak ada Minat & & 7 & 6,6 & Tidak menyulitkan \\
& Tidak ada Perhatian & 10 & 9,4 & Tidak menyulitkan \\
& $\begin{array}{l}\text { Kesehatan terganggu pada } \\
\text { saat praktikum }\end{array}$ & 8 & 7,5 & Tidak menyulitkan \\
\hline
\end{tabular}

Tabel 4.2 Tingkat kesulitan mahasiswa melaksanakan praktikum dari faktor eksternal

\begin{tabular}{|c|c|c|c|c|c|}
\hline Faktor & Indikator & $\begin{array}{l}\text { Jml } \\
\text { Respon } \\
\text { den }\end{array}$ & Frekuensi & $\begin{array}{l}\text { Persentase } \\
\text { Kesulitan } \\
\text { kegiatan } \\
\text { praktikum } \\
\end{array}$ & $\begin{array}{c}\text { Kategori tingkat } \\
\text { kesulitan } \\
\text { melaksanakan } \\
\text { praktikum } \\
\end{array}$ \\
\hline \multirow[t]{16}{*}{ Eksternal } & Tidak ada alat & 106 & 58 & 55 & Cukup menyulitkan \\
\hline & Tidak ada bahan & & 15 & 14 & Tidak menyulitkan \\
\hline & $\begin{array}{l}\text { Tidak ada petunjuk } \\
\text { praktikum }\end{array}$ & & 7 & 7 & Tidak menyulitkan \\
\hline & Ketidakhadiran dosen & & 62 & 58 & Cukup menyulitkan \\
\hline & $\begin{array}{l}\text { Ketidakjelasan penjelasan } \\
\text { co As }\end{array}$ & & 32 & 30 & kurang menyulitkan \\
\hline & Ketidakhadiran Co.AS & & 6 & 6 & Tidak menyulitkan \\
\hline & $\begin{array}{l}\text { Tidak ada pelayanan } \\
\text { Laboran }\end{array}$ & & 15 & 14 & Tidak menyulitkan \\
\hline & Materi praktik banyak & & 19 & 18 & Tidak menyulitkan \\
\hline & Soal praktikum banyak & & 7 & 7 & Tidak menyulitkan \\
\hline & $\begin{array}{l}\text { Soal praktikum tidak sesuai } \\
\text { dengan materi praktek }\end{array}$ & & 12 & 11 & Tidak menyulitkan \\
\hline & $\begin{array}{l}\text { Hasil pretes dan postes tidak } \\
\text { dikembalikan ke mahasiswa }\end{array}$ & & 34 & 32 & Kurang menyulitkan \\
\hline & Jadwal praktek padat & & 19 & 18 & Tidak menyulitkan \\
\hline & Laporan terlalu banyak & & 31 & 29 & kurang menyulitkan \\
\hline & $\begin{array}{l}\text { Petunjuk praktek disusun } \\
\text { kurang baik }\end{array}$ & & 15 & 14 & Tidak menyulitkan \\
\hline & $\begin{array}{l}\text { Tidak ada koordinasi dosen } \\
\text { co as dan laboran }\end{array}$ & & 19 & 18 & Tidak menyulitkan \\
\hline & Suasana lab tidak nyaman & & 64 & 60 & Cukup menyulitkan \\
\hline
\end{tabular}

Faktor eksternal pada indikator penjelasan co assisten yang kurang baik, hasil pretes dan postes yang tidak dikembalikan serta laporan yang terlalu banyak kurang mempengaruhi kesulitan praktikum sedangkan ketidaknyamanan ruang praktikum, kehadiran pembimbing dan ketidakadaan alat cukup 
mempengaruhi kegiatan praktikum. Kondisi belajar yang optimal dapat tercapai jika pembimbing mampu mengatur peserta didiknya dan menyediakan sarana dan prasarana serta mengendalikannya dalam suasana yang menyenangkan agar peserta didik dapat mencapai tujuan kegiatan yang ingin dicapai $[9,10]$. Kesulitan praktikum yang dialami mahasiswa diperlukan solusi agar hasil kegiatan praktikum sesuai harapan yaitu tercapai tujuan praktikumnya. Hasil belajar yang tinggi dikatakan telah belajar dengan baik, sebaliknya jika siswa yang mendapat hasil belajar yang rendah karena tidak belajar dengan baik atau mengalami kesulitan belajar [11].

\section{KESIMPULAN DAN SARAN \\ Kesimpulan}

Berdasarkan hasil penelitian dapat disimpulkan bahwa kesulitan yang dihadapi mahasiswa dalam melaksanakan kegiatan praktikum di laboratorium PMIPA FKIP Unram secara berurutan dari tingkat kesulitan yang besar adalah ruang praktikum yang kurang nyaman, kehadiran dosen pembimbing rendah, kekurangan alat praktikum, hasil pretes dan postes tidak dikembalikan ke praktikan, kurang paham dengan penjelasan co assisten tentang materi praktikum dan terlalu banyak jenis laporan praktikum.

\section{Saran}

Kesulitan-kesulitan yang dihadapi mahasiswa dalam melaksanakan kegiatan praktikum supaya diperhatikan oleh stake holder yang ada sehingga kedepannya kesulitan kesulitan tersebut dapat diatasi. Terimakasih penulis sampaikan kepada Rektor Universitas Mataram atas dukungan melalui pemberian dana PNBP dalam melaksanakan kegiatan penelitian ini.

\section{DAFTAR PUSTAKA}

[1] Darminto, (2006). Pembelajaran Kimia yang Berkualitas. Jurnal Kimia dan Pendidikan Kimia "Chemica", Edisi Khusus 2 Oktober 2006, Universitas Negeri Makassar.
[2] Faika, S., \& Side, S. (2013). Analisis kesulitan mahasiswa dalam perkuliahan dan praktikum kimia dasar di jurusan kimia FMIPA Universitas Negeri Makassar. Chemica: Jurnal Ilmiah Kimia dan Pendidikan Kimia, 12(2), 18-26.

[3] Siregar, W. Z. (2015). Kampus, Masyarakat Dan Perubahan: Aku Dan Pengalaman Belajar Bersama Sile/Lld Project.

[4] Ulfah, A. (2018). Pengaruh Aspek Komunikasi Efektif Petugas Laboratorium terhadap Kepuasan Pasien Rawat Jalan di Rumah Sakit Panti Waluyo Surakarta. Skripsi. Program Studi D-IV Analis Kesehatan, Fakultas Ilmu Kesehatan, Universitas Setia Budi (Doctoral dissertation, Universitas Setia Budi Surakarta).

[5] Slameto. 2010. Belajar Dan Faktor-Faktor Yang Mempengaruhi, Jakarta : Rineka Cipta.

[6] Simamora, B. (2002). Panduan riset perilaku konsumen. Gramedia Pustaka Utama.

[7] Hidayati, F. 2010. Kajian Kesulitan Belajar Siswa Kelas VII SMP Negeri 16 Yogyakarta dalam Mempelajari Aljabar. Yogyakarta: UNY Press.

[8] Susilana, R., \& Riyana, C. (2008). Media pembelajaran: hakikat, pengembangan, pemanfaatan, dan penilaian. CV. Wacana Prima.

[9] Aisyah, S. (2015). Perkembangan peserta didik dan bimbingan belajar. Deepublish.

[10] Khaerunnisa, B. S., Kusmiyati, K., \& Ilhamdi, M. L. (2019). Analisis Tingkat Kesulitan Yang Dialami Peserta Didik Dalam Praktikum Biologi di SMA. Jurnal Pijar Mipa, 14(1), 2328.

[11] Ilhamdi, M. L., Santoso, D., \& Astuti, S. P. (2020). Penerapan Metode Problem Based Learning Untuk Meningkatkan Hasil Belajar Biologi Mata Pelajaran Lintas Minat. Jurnal Pijar Mipa, 15(2), 135-139.

[12] Arikunto, S. (2013). Prosedur Penelitian: Suatu Pendekatan Praktik. Jakarta: Rineka Cipta.

[13] Sugiono. (2008). Metode Penelitian Kuantitatif Kualitatif dan $R \& D$, Bandung: Alfabeta. 